\title{
ERRATUM
}

\section{Familial Mediterranean fever is no longer a rare disease in Italy}

Micaela La Regina, Gabriella Nucera, Marialuisa Diaco, Antonio Procopio, Giovanni Gasbarrini, Cecile Notarnicola, Isabelle Kone-Paut, Isabelle Touitou and Raffaele Manna

European Journal of Human Genetics (2003) 11, 550. doi:10.1038/sj.ejhg.5200999

Correction to: European Journal of Human Genetics (2003) 11, 50-56. doi:10.1038/sj.ejhg.5200916

We would like to apologise that due to an oversight in the above article, Table 4 was omitted in this article.

Below it is reproduced with the relevant legend.

Table 4 Genotype distribution in 71 Italian patients

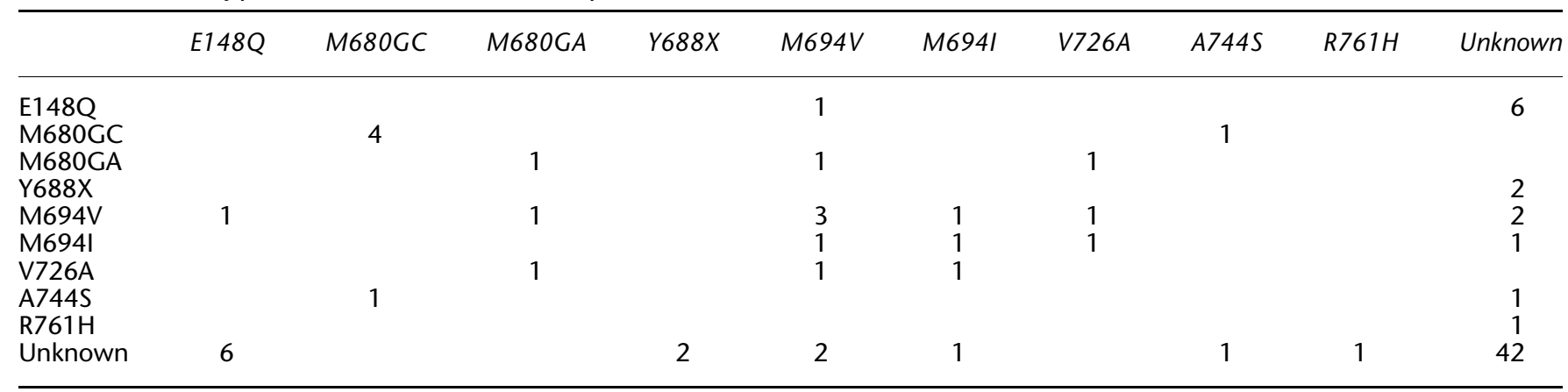

